O impacte urbanístico e socioeconómico do Alojamento Local na cidade de Lisboa

Raul Lopes

Setembro 2018

WP n. 0 2018/05

DOCUMENTO DE TRABALHO

WORKI NG PAPER

DINAMIR'CET

CENTAD DE ESTUDOS SOBREA MUDANCCA
SOCIOECONOMICA E O TERAITOAIO

ISCTE-IUL

ISCTE IUL

Instituto Universitário de Lisboa

FCT 


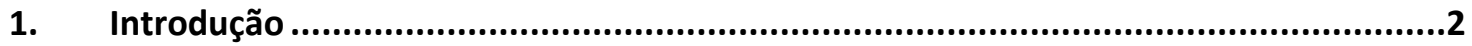

2. Representatividade e características da amostra em estudo ..................................3

3. $\mathrm{O}$ tecido empresarial do AL: dinâmica económica versus social.................................5

4. O impacte urbanístico do AL na cidade de Lisboa ................................................11

5. Conclusões e implicações para as Políticas Públicas .............................................20

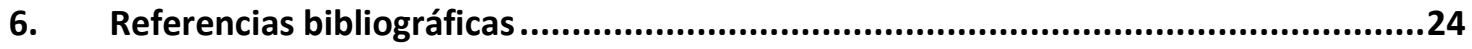

1 Economista, Professor no ISCTE-IUL, Instituto Universitário de Lisboa. O autor agradece a leitura atenta e os comentários feitos pelo referee que anonimamente apreciou este texto, e, por outro lado, declara que não tem qualquer relação económica com a atividade turística, nomeadamente com o Alojamento Local. Investigador DINÂMIA'CET - IUL. 


\section{O impacte urbanístico e socioeconómico do Alojamento Local na cidade de Lisboa}

\section{INTRODUÇÃO}

O tema Alojamento Local (AL) tornou-se recorrente na agenda mediática e política portuguesa, especialmente tendo como referência a cidade de Lisboa. Não obstante a popularidade do assunto, o papel do AL está longe de ser consensual. Se para uns o AL tem o mérito de ter contribuído para a redinamização económica da cidade, para outros, o AL é apontado como o responsável pela expulsão dos residentes do centro da cidade.

Apesar da relevância das questões envolvidas na dinâmica de crescimento do AL, escasseiam os estudos sobre a realidade envolvente do AL, bem assim a informação estatística de suporte à sua análise ${ }^{2}$. Em grande medida o debate tem vindo a basear-se em juízos de opinião. Em face desta situação, decidiuse realizar um inquérito direto aos proprietários de estabelecimentos de AL em Lisboa, com dois objetivos principais: i. analisar o efeito socioeconómico do alojamento local $^{3}$; ii. analisar o impacte urbanístico do AL na cidade.

\footnotetext{
${ }^{2}$ As exceções mais meritórias são os trabalhos coordenados por Hélia Pereira a convite da AHRESP

3 A análise acabou por incidir exclusivamente sobre as características socioeconómicas dos proprietários e a importância do rendimento do $\mathrm{AL}$, já que as respostas obtidas relativamente ao tempo de trabalho despendido com o AL estão manifestamente exageradas.

DINÂMIA'CET - IUL, Centro de Estudos sobre a Mudança Socioeconómica e o Território do Instituto Universitário de Lisboa (ISCTE-IUL)$$
\text { Sala } 2 \text { W4 - D | ISCTE-IUL - Av. das Forças Armadas }
$$$$
\text { 1649-026 Lisboa, PORTUGAL }
$$

Tel. (+351) 210464031 - Extensão 293101 | E-mail: dinamia@iscte-iul.pt | www.dinamiacet.iscte-iul.pt
} 


\section{REPRESENTATIVIDADE E CARACTERÍSTICAS DA AMOSTRA EM ESTUDO}

Não se conhece com rigor o número de espaços de AL existentes em Portugal, ou mesmo na cidade de Lisboa. Cruzando a informação das entidades oficiais com a das plataformas digitais de comercialização do aluguer de alojamento, conclui-se que existirão em Lisboa cerca de 20 mil espaços de AL, pouco mais de metade dos quais referenciados pelas autoridades administrativas. O elevado grau de informalidade desta atividade explica uma certa cultura de clandestinidade que se respira nas redes sociais animadas por proprietários de AL. Em consequência, sabe-se pouco da realidade do negócio do AL na cidade, mas se alguém promove a recolha de informação sobre a realidade do AL, é recebido com desconfiança. Seja como for, inseridos na economia legalizada ou na economia informal, cerca de 3/4 do turismo de alojamento local em Portugal deverá localizar-se no Algarve (40\%) e nas cidades de Lisboa (25\%) e do Porto (10\%). É, portanto, um processo geograficamente concentrado em zonas urbanas de vocação turística, parecendo não ter grande penetração nos espaços rurais. A ausência de políticas públicas orientadas especificamente para esta atividade nas zonas rurais, explicará a fraca expressão rural do AL, pese embora o elevado potencial turístico de muitos dos nossos espaços rurais.

O questionário, que constitui a fonte da informação subjacente a este texto, foi enviado por email no final de 2017 a cerca de 5 mil entidades, proprietárias de mais de 10 mil espaços de AL na cidade de Lisboa, tendo por referência a base de dados oficial existente. Esse email convidava as pessoas a responderem de forma anónima ao referido questionário, entretanto colocado numa plataforma online. Obtiveram-se 410 respostas, o que corresponde a aproximadamente $8 \%$ de taxa de resposta. Das respostas obtidas, cerca de duas dezenas foram eliminadas, por não terem resistido aos testes de coerência interna realizados individualmente às respostas recebidas. A baixa recetividade dos proprietários ao inquérito poderá justificar-se pela insistência com que o AL tem sido notícia nos media, normalmente veiculando uma imagem negativa do AL, e/ou pela atmosfera de informalidade que envolve a atividade. Não obstante, de acordo com os procedimentos de cálculo estatístico habituais, a amostra obtida é adequadamente representativa do universo de 20 mil espaços de AL que se estima existam na cidade de Lisboa, contendo uma margem máxima de erro de $4,9 \%$ com $95 \%$ de grau de confiança.

Estes parâmetros estatísticos são convergentes com outros de caracterização da amostra por referência ao universo oficialmente identificado, conforme pode observar-se na tabela seguinte. Tomando como referência o universo referenciado pelo Turismo de Portugal (TP, 2017), que é a base de dados mais completa das possuídas pelas entidades públicas em Portugal, a amostra replica muito satisfatoriamente o padrão de localização dos estabelecimentos de AL na cidade. A grande concentração (45\%) encontra-se

\footnotetext{
DINÂMIA'CET - IUL, Centro de Estudos sobre a Mudança Socioeconómica e o Território

do Instituto Universitário de Lisboa (ISCTE-IUL)

Sala 2W4 - D | ISCTE-IUL - Av. das Forças Armadas

1649-026 Lisboa, PORTUGAL

Tel. (+351) 210464031 - Extensão 293101 | E-mail: dinamia@iscte-iul.pt | www.dinamiacet.iscte-iul.pt
} 
na zona do "Centro Histórico", correspondendo às freguesias de St ${ }^{\mathrm{a}}$ Maria Maior e Misericórdia. Segue-se o "Arco Central”, aqui definido pelas freguesias de Estrela, $\mathrm{St}^{\circ}$ António, Arroios e S. Vicente, onde se localizam $30 \%$ dos estabelecimentos inquiridos. Finalmente, as restantes freguesias da cidade acolhem $25 \%$.

Tabela 1 - Caracterização da amostra versus universo: perfil dos proprietários e localização dos estabelecimentos

\begin{tabular}{|c|c|c|}
\hline & Universo & Amostra \\
\hline \multicolumn{3}{|l|}{ Padrão de localização na cidade } \\
\hline Centro histórico & 48 & 45 \\
\hline Arco Central & 33 & 30 \\
\hline Coroa Exterior & 19 & 25 \\
\hline \multicolumn{3}{|l|}{ Perfil dos proprietários } \\
\hline Número médio de $\mathrm{AL}$ & 2 & 1,97 \\
\hline$\%$ de proprietários apenas com $1 \mathrm{AL}$ & 71 & 70,5 \\
\hline Capacidade média de alojamento ( $\mathrm{N}^{\circ}$ pessoas) & 11,5 & 10,8 \\
\hline $\begin{array}{l}\text { \% de proprietários apenas com } 1 \text { AL com capacidade máxima para } \\
4 \text { hóspedes }\end{array}$ & 40 & 45 \\
\hline$\%$ de gestores com um máximo de 3 AL e 10 hóspedes & 76 & 79 \\
\hline
\end{tabular}

Fonte: cálculos do autor com base em inquérito próprio e TP (2017)

Em termos gerais estamos a falar de espaços de alojamento em que 2/3 correspondem a apartamentos cuja tipologia é um T1 ou T2. Há, todavia, proprietários com mais do que um apartamento. De acordo com o responsável ibérico da AirBnB (Público, 2017), "mais de 70\% dos anfitriões só tem um anúncio", o que é corroborado pela nossa amostra (vd Tabela 1). Porém, se 70\% dos proprietários tem apenas um AL, $18 \%$ tem 2 ou 3, havendo $12 \%$ que são proprietários de pelo menos 4 espaços distintos, de onde resulta um valor médio de 2 espaços de AL por entidade. Desta segmentação decorre uma aparente contradição:

- Na tipologia de AL predominam os pequenos espaços: 63\% dos AL têm capacidade para alojar no máximo 4 pessoas. Apenas $9 \%$ têm capacidade para mais de 10 pessoas 
- Porém, quando se considera a totalidade dos espaços de AL de um mesmo proprietário, a oferta de pequena escala perde algum peso para a oferta de maior dimensão. Há quase metade $(45 \%)$ de proprietários que consegue alojar no máximo 4 pessoas, enquanto $25 \%$ deles tem capacidade para alojar (no mesmo espaço ou em vários) pelo menos 10 pessoas, o que afeta significativamente o valor médio da capacidade de alojamento (11 pessoas).

Tabela 2 - Distribuição dos proprietários de acordo com a capacidade total de alojamento

\begin{tabular}{c|c|c} 
& Valid Percent & $\begin{array}{c}\text { Cumulative } \\
\text { Percent }\end{array}$ \\
\hline$=<3$ pessoas & 18,2 & 18,2 \\
\hline 4 pessoas & 28,6 & 46,8 \\
\hline $5-9$ pessoas & 27,5 & 74,3 \\
\hline $10-19$ pessoas & 13,2 & 87,5 \\
\hline$>=20$ pessoas & 12,5 & 100,0 \\
\hline Total & 100,0 & \\
\hline
\end{tabular}

Fonte: cálculos do autor com base em inquérito próprio

Estes números sugerem que a atividade do AL está associada a um tecido empresarial segmentado, havendo $1 / 4$ dos proprietários com capacidade para alojar mais de 10 pessoas, ou mesmo mais de 20 pessoas (em $12,5 \%$ dos casos).

\section{O TECIDO EMPRESARIAL DO AL: DINÂMICA ECONÓMICA VERSUS SOCIAL}

A segmentação suprarreferida justifica que nos detenhamos na clarificação do perfil dos proprietários de AL na cidade de Lisboa.

Tomando por base a informação da Tabela 3, a relação com a propriedade confirma a segmentação já identificada. Com efeito, só $47 \%$ dos AL são geridos pelo proprietário do respetivo imóvel. A maioria (53\%) dos AL correspondem a espaços explorados sob arrendamento, ainda que na maioria dos casos se trate de um negócio pessoal, conforme se pode deduzir do facto de apenas $28 \%$ dos gestores de AL serem pessoas coletivas.

Esta segmentação do tecido empresarial do AL reflete-se igualmente no rendimento auferido com a atividade. O valor médio, apesar de considerável, cerca de 22 mil euros/ano, não é generalizável. A 
maioria (58\%) dos proprietários obtém pouco mais de mil euros por mês, havendo $55 \%$ dos proprietários para quem o AL é uma fonte de rendimento complementar ao salário/reforma.

Tabela 3 - Perfil dos proprietários

\begin{tabular}{|l|c|}
\hline Indicador & Valor \\
\hline \% de Alojamentos, geridos pelo proprietário do edifício & 47 \\
\hline \% de Alojamentos, geridos por arrendatários & 53 \\
\hline \% de gestores "Pessoas singulares" & 72 \\
\hline \% de gestores "Pessoas coletivas" & 28 \\
\hline Rendimento anual médio & $22400 €$ \\
\hline \% de proprietários que auferem do AL no máximo 15 mil euros/ano & 58 \\
\hline \% de proprietários que têm um emprego ou uma reforma & 55 \\
\hline
\end{tabular}

Fonte: cálculos do autor com base em inquérito próprio e TP (2017)

Estes números sugerem que a distribuição do rendimento do AL é muito assimétrica. Apesar de, como se disse, a receita bruta anual média estimada ser da ordem dos 22 mil euros, apenas $24 \%$ dos proprietários auferem mais de 25 mil euros/ano, sendo que $11 \%$ recebem mesmo mais de 70 mil euros. Em contrapartida, 36\% dos AL não conseguem gerar sequer 10 mil euros/ano. Resumindo, em termos de rendimento o negócio do AL segmenta-se em três grupos distintos: um grupo (36\%) que recebe do AL menos de 10 mil euros/ano, isto é, no máximo cerca de 75\% do salário médio em Portugal; outro grupo (40\%) que obtém entre 10 e 25 mil euros, ou seja, um valor médio 30\% superior ao salário médio; um terceiro grupo ((24\%) que retira do negócio mais de 25 mil euros por ano, o que corresponde a pelo menos 2 salários médios.

A análise do contributo das receitas do AL para o orçamento familiar confirma o padrão economicamente assimétrico do AL, mas também a grande relevância social da atividade (Vd Tabela 4). Por um lado, há 30\% dos proprietários que vive apenas do AL ou obtém daqui mais de metade do rendimento familiar, mas, em contrapartida, para 34\% dos proprietários as receitas do AL são apenas um complemento de rendimento inferior a $1 / 4$ do orçamento familiar. Daqueles que auferem do AL a maioria do rendimento familiar, metade (52\%) tem na atividade turística a sua única fonte de rendimento. Noutros termos, para $70 \%$ dos proprietários o AL é um complemento (inferior a 50\%) do rendimento familiar. Trata-se de pessoas que têm um emprego ou estão reformados e que obtém do AL menos de metade do seu rendimento familiar. Estes números são bem reveladores da importância social do principal segmento do AL na cidade de Lisboa.

\footnotetext{
DINÂMIA'CET - IUL, Centro de Estudos sobre a Mudança Socioeconómica e o Território do Instituto Universitário de Lisboa (ISCTE-IUL)$$
\text { Sala 2W4 - D | ISCTE-IUL - Av. das Forças Armadas }
$$$$
\text { 1649-026 Lisboa, PORTUGAL }
$$ 
A estimativa realizada com base no inquérito aponta para que o rendimento global das famílias proprietárias de AL se distribua de forma equivalente pelos vários escalões do IRS de 2017 (à exceção do $1^{\circ}$ escalão), o que reforça a ideia de que em boa medida o AL tem funcionado como um complemento de rendimento da classe média, que encontrou nesta atividade um refúgio para a perda de rendimento provocada pela política de austeridade adotada em Portugal a partir de 2010 . Note-se que $49 \%$ dos proprietários inquiridos estão nos 3 escalões mais baixos de IRS, e que o limite superior do $3^{\circ}$ escalão (40522€) corresponde sensivelmente ao rendimento de uma família com duas pessoas empregadas a auferir um salário equivalente a 1,5 do valor do salário médio em Portugal.

Tabela 4 - Importância das receitas do AL no rendimento familiar (Unidade: \% do número total de AL)

\begin{tabular}{|ll|llc|}
\hline \multicolumn{2}{|c|}{ Receitas do AL } & \multicolumn{3}{|c|}{$\begin{array}{c}\text { Proporção do rendimento familiar } \\
\text { proveniente do AL }\end{array}$} \\
\hline (escalão) & $\%$ & $<25 \%$ & $25-50 \%$ & $>50 \%$ \\
\hline & $36 \%$ & $16 \%$ & $12 \%$ & $8 \%$ \\
\hline $10-25$ mil $€$ & $40 \%$ & $12 \%$ & $17 \%$ & $11 \%$ \\
\hline$>25$ mil $€$ & $24 \%$ & $6 \%$ & $7 \%$ & $11 \%$ \\
\hline TOTAL & $100 \%$ & $34 \%$ & $36 \%$ & $30 \%$ \\
\hline
\end{tabular}

Fonte: cálculos do autor com base em inquérito próprio

Quando se cruza o valor das receitas do AL com o rendimento familiar (Tabela 4) a importância social do AL é ainda mais evidente:

i. Como se sublinhou, $36 \%$ dos espaços de AL geram menos de 10 mil euros de receita por ano. Apesar desta receita ser pequena, para $20 \%$ dos proprietários ela representa ainda assim mais de $1 / 4$ do seu rendimento familiar (em $8 \%$ dos casos representa mesmo mais de metade).

ii. Há $28 \%$ de proprietários que auferem 10 a 25 mil euros de receita, para quem isso representa também mais de $1 / 4$ do rendimento familiar.

iii. De entre aqueles para quem o AL representa a fonte de menos de $1 / 4$ do rendimento familiar (34\% do total) observa-se que na maioria dos casos não é o elevado rendimento familiar (extra AL) que 
explica esta pequena importância, mas sim o reduzido volume de receitas provenientes do AL. Quase metade dos AL nesta situação geram menos de 10 mil euros/ano.

As assimetrias do tecido empresarial associado ao AL que temos vindo a sublinhar, justificam um esforço de síntese que nos permita aferir a tipologia de negócios ligados ao AL e o seu peso relativo. Para tal procedemos ao cruzamento do número total de estabelecimentos que cada agente possui com a capacidade total de alojamento correspondente.

Tabela 5 - Tipologia empresarial do Alojamento Local em Lisboa

\begin{tabular}{|c|c|c|c|c|}
\hline \multirow[b]{2}{*}{$\mathrm{N}^{\mathrm{o}}$ de Estabelecimentos } & \multicolumn{3}{|c|}{ Capacidade ( $\mathrm{N}^{\circ}$ de hóspedes) } & \multirow[b]{2}{*}{$>=20$} \\
\hline & $=<4$ & $=<10$ & 10 a 20 & \\
\hline 1 & $\begin{array}{l}\text { Micronegócio } \\
A=45 \% \\
(40 \%)\end{array}$ & & & \\
\hline $1-3$ & & $\begin{array}{l}\text { Negócio familiar } \\
\mathrm{B}=34 \% \\
(36 \%)\end{array}$ & & \\
\hline $1-5$ & & & $\begin{array}{l}\text { Pequena empresa } \\
\mathrm{C}=8 \% \\
(10 \%)\end{array}$ & \\
\hline$>5$ & & & & $\begin{array}{l}\text { Média empresa } \\
D=13 \% \\
(14 \%)\end{array}$ \\
\hline
\end{tabular}

( \% ) = Universo. A, B, C, D = Amostra

Fonte: cálculos do autor com base em inquérito próprio e TP (2017)

A Tabela 5 mostra o número de AL da amostra em estudo integrados em cada uma das tipologias, em percentagem do total de AL. Entre parêntesis indica-se o correspondente valor de cada grupo quando se faz o exercício com a totalidade dos estabelecimentos oficialmente registados (TP, 2017). Corroborando a boa representatividade da amostra inquirida, os resultados obtidos são convergentes com os do universo.

Os números desta Tabela proporcionam-nos uma boa síntese do tecido empresarial do AL em Lisboa:

i. Desde logo revelando que $45 \%$ dos espaços de AL que estamos a analisar correspondem a simples micronegócios que funcionam como fonte complementar de rendimento para o 
proprietário. Incluíram-se neste grupo os proprietários que apenas possuem 1 apartamento com uma capacidade máxima de alojamento de 4 hóspedes.

ii. O segundo grupo mais importante (34\%) é constituído por pessoas com uma capacidade de alojamento máxima de 10 pessoas, eventualmente distribuída por vários espaços, nunca mais do que 3. Neste caso o AL já se apresenta como algo mais do que mero complemento de rendimentos, mas, pela sua dimensão económica, não passa de um negócio familiar.

iii. Finalmente, identificam-se dois grupos cuja capacidade de alojamento confere ao negócio uma dimensão empresarial, nuns casos correspondendo a pequenas empresas, noutro de médias ou até grandes empresas (algumas, poucas, dispõem de dezenas de alojamentos). Conjuntamente, estes dois grupos para quem o AL é um negócio de natureza empresarial, representarão menos de 1/4 dos estabelecimentos de AL na cidade, aqui se incluindo antigas pensões e outros espaços a funcionar como hostels.

A Tabela 6 inclui alguns indicadores que, por um lado, confirmam a consistência dos 4 grupos definidos, e, por outro lado, reforçam a ideia de que estamos em presença de um tecido empresarial segmentado onde a um pequeno grupo de empresas se contrapõe uma esmagadora maioria de negócios de génese familiar, evidenciando a relevância social de cerca de mais de $3 / 4$ dos espaços de AL existentes na cidade de Lisboa.

Tabela 6 - Perfil da tipologia empresarial definida

\begin{tabular}{|c|c|c|c|c|}
\hline & A Micronegócio & $\begin{array}{l}\text { B Negócio } \\
\text { familiar }\end{array}$ & $\begin{array}{l}\text { C Pequena } \\
\text { empresa }\end{array}$ & \begin{tabular}{|l}
$\mathrm{D}$ \\
Média \\
empresa
\end{tabular} \\
\hline Capacidade de alojamento típica ( $\mathrm{N}^{\circ}$ hóspedes) & 4 & 6 & $12-14$ & $>30$ \\
\hline$\%$ de gestores que são proprietários do edifício & 75 & 64 & 37 & 27 \\
\hline$\%$ de gestores que são pessoa coletiva & 12 & 23 & 49 & 74 \\
\hline$\%$ de proprietários/gestores que têm um emprego/reforma & 66 & 52 & 53 & 24 \\
\hline$\%$ de AL que geram menos de 15 mil euros/ano & 83 & 47 & 38 & 8 \\
\hline$\%$ de AL que geram mais de 25 mil euros/ano & 4 & 27 & 44 & 74 \\
\hline$\%$ de proprietários/gestores no $5^{\circ}$ escalão do IRS ( $>80$ mil€) & 12 & 25 & 29 & 75 \\
\hline
\end{tabular}

Fonte: cálculos do autor com base em inquérito próprio 
Tipicamente, o grupo do "micronegócio" é composto por pessoas que exploram o seu próprio apartamento, onde alojam até 4 hóspedes, auferindo menos de 15 mil euros por ano do AL, rendimento que funciona como complemento ao salário ou à pensão/reforma que auferem. São pessoas integradas nos 3 escalões mais baixos do IRS (62\%). Em contrapartida, o grupo de maior dimensão económica (D) integra $3 / 4$ de pessoas que vivem exclusivamente do $\mathrm{AL}$ ou que juntam o rendimento do AL ao de outros negócios. Têm capacidade para alojar mais de 30 pessoas em simultâneo, e a gestão do negócio é feita por uma estrutura empresarial. Cerca de 3/4 deles recebem do AL pelo menos 25 mil euros/ano, e integram o escalão de IRS mais elevado. Ou seja, quando se considera o rendimento da família estratificado de acordo com os escalões de aplicação do IRS 2017, fica perfeitamente claro o perfil socialmente dicotómico dos grupos analíticos definidos. Enquanto no grupo de maior dimensão empresarial $75 \%$ dos proprietários pertencem a famílias que auferem um rendimento global anual superior a 80 mil euros, no Grupo de microdimensão há $62 \%$ de proprietários cujas famílias têm um rendimento anual inferior a 40 mil euros.

Os outros dois grupos correspondem a uma realidade intermédia, normalmente mais próxima da tipologia do micronegócio, ainda que o grupo C, "pequena empresa" apresente maior semelhança com o grupo D no que respeita à forma empresarial de exploração e à utilização de espaços arrendados para utilização comercial.

A análise simultânea do grupo e do rendimento auferido do AL permite reforçar a ideia de que o grupo A, o maioritário, é um grupo de micronegócio: 83\% dos proprietários inseridos neste grupo recebem menos de 15 mil euros/ano do AL. O grupo B não está muito longe deste perfil: 69\% dos proprietários deste grupo não recebe do AL mais do que 10 a 50 mil euros/ano. Já o grupo C tem 54\% de pessoas a obter mais de 25 mil euros, e no grupo D, 64\% recebem mais de 70 mil euros.

Em síntese, nos dois primeiros grupos socioeconómicos (que correspondem a $3 / 4 \mathrm{dos}$ espaços de AL) o negócio do AL tem claramente uma função de complemento do rendimento familiar obtido do trabalho: no grupo A, $80 \%$ dos proprietários recebem do AL menos de metade do rendimento familiar. No grupo B, o AL representa menos de 50\% do rendimento familiar para $69 \%$ dos proprietários. Pelo contrário, para os dois Grupos de maior dimensão empresarial (que representam cerca de 1/4 do total da atividade), o AL é essencialmente um negócio. Para $3 / 4$ dos proprietários nestes grupos o AL constitui a origem de pelo menos $25 \%$ do rendimento familiar. E para quase metade (45\% no grupo C e $52 \%$ no grupo D) o AL é responsável por mais de metade do rendimento da família. 


\section{O IMPACTE URBANÍSTICO DO AL NA CIDADE DE LISBOA}

O efeito mais evidente do turismo na cidade é a omnipresença de estrangeiros, especialmente nos bairros tradicionais. Parece que Portugal, e Lisboa em especial, passaram a estar na rota do turismo mundial, a ponto de já se ouvirem queixas de nacionais sobre o alegado excesso de turistas. Será que há um desmesurado crescimento do turismo em Portugal?

A informação do Banco Mundial (Tabela 7) revela que nas duas últimas décadas houve um grande crescimento do número de visitantes quer na UE quer nos dois principais destinos mundiais do turismo: França e EUA. Mas mostra igualmente que a Península Ibérica passou a ser um dos destinos privilegiados pelos turistas, a ponto de Espanha se ter tornado no $3 .^{\circ}$ maior destino mundial. Ou seja, o crescimento do turismo em Portugal (139\% entre 1995 e 2016) insere-se numa dinâmica de crescimento mundial do turismo em que a Península Ibérica ocupa lugar central. O aumento do número de visitantes em Portugal (que ultrapassou o número de residentes) foi, do ponto de vista relativo, semelhante ao acréscimo verificado quer em Espanha, quer no conjunto dos países do mundo.

Tabela 7 - Número de visitantes estrangeiros

\begin{tabular}{|l|l|l|l|}
\hline Países & $\begin{array}{l}\text { 1995 } \\
\text { milhões }\end{array}$ & $\begin{array}{l}2016 \\
\text { milhões }\end{array}$ & $\begin{array}{l}2016 / 1995 \\
\%\end{array}$ \\
\hline França & 60 & 83 & 38,3 \\
USA & 43 & 76 & 76,7 \\
Espanha & 33 & 76 & 130,3 \\
$\ldots$ & 4,6 & 11 & 139,1 \\
Portugal & & 482 & 86,1 \\
UE & 259 & 1245 & 137,6 \\
Mundo & 524 & 4 & \\
\hline
\end{tabular}

World Bank (2017) World Development Indicators

E Lisboa, terá turistas em excesso? Com 505 mil habitantes, em 2017 Lisboa recebeu 4 milhões de hóspedes na hotelaria tradicional, dos quais $75 \%$ são estrangeiros, ou seja, 3 milhões de estrangeiros (INE, 2017). Quando se compara este número com o registado pelas cidades que constituem os principais destinos europeus do turismo (Tabela 8), de imediato nos damos conta de que a procura turística de Lisboa está muito aquém da registada, não apenas em cidades globais como Londres e Paris, mas igualmente em cidades demograficamente comparáveis a Lisboa, como sejam especialmente Dublin e

\footnotetext{
DINÂMIA'CET - IUL, Centro de Estudos sobre a Mudança Socioeconómica e o Território do Instituto Universitário de Lisboa (ISCTE-IUL)$$
\text { Sala 2W4 - D | ISCTE-IUL - Av. das Forças Armadas }
$$$$
\text { 1649-026 Lisboa, PORTUGAL }
$$

Tel. (+351) 210464031 - Extensão 293101 | E-mail: dinamia@iscte-iul.pt | www.dinamiacet.iscte-iul.pt
} 
Amesterdão ${ }^{4}$. Tal sugere que sendo embora elevado o número de turistas na cidade, não pode considerarse que o mesmo seja excessivo, sendo aliás previsível que continue a crescer, dadas as tendências estruturais da procura turística mundial.

Seja como for, é um facto que Lisboa tem hoje uma grande dinâmica turística, que não raro surge na imprensa local como um processo de desqualificação da cidade atribuído à proliferação de estabelecimentos de AL na cidade. Esta é uma questão fundamental que importa discutir, desde logo esclarecendo qual é o peso relativo do AL no conjunto da procura turística.

Tabela 8 - Top 10 cidades europeias com mais visitantes estrangeiros, 2017

\begin{tabular}{|c|c|c|}
\hline Cidades & $\begin{array}{l}\text { Milhões de } \\
\text { turistas } \\
\text { estrangeiros }\end{array}$ & \begin{tabular}{|l} 
Milhões \\
de \\
residentes \\
na \\
“cidade"
\end{tabular} \\
\hline Londres & 20 & 7.4 \\
\hline Paris & 16 & 2.2 \\
\hline Barcelona & 9 & 1.6 \\
\hline Amesterdão & 9 & 0.8 \\
\hline Milão & 8 & 1.3 \\
\hline Roma & 7 & 2.6 \\
\hline Viena & 7 & 1.6 \\
\hline Praga & 6 & 1.2 \\
\hline Dublin & 6 & 0.5 \\
\hline Madrid & 6 & 3.2 \\
\hline \multicolumn{3}{|l|}{$\ldots$} \\
\hline Lisboa & 3 & 0.5 \\
\hline
\end{tabular}

https://www.independent.co.uk e Eurostat

Tomando como base os dados oficiais mais recentes (2016), conclui-se que existem em Lisboa mais de 51 mil camas, gerando mais de 11 milhões de dormidas por ano na hotelaria convencional (Tabela 9). Nestes números está incluído o que o INE classifica de Alojamento Local, mas que na verdade

4 Tenha-se presente que o número de turistas é comparável pois estes dirigem-se essencialmente para a zona histórica da cidade, independentemente da unidade de referenciação geográfica. Já a população residente é influenciada por critérios de delimitação administrativa do que em cada caso se inclui como espaço geográfico na "cidade".

\footnotetext{
DINÂMIA'CET - IUL, Centro de Estudos sobre a Mudança Socioeconómica e o Território do Instituto Universitário de Lisboa (ISCTE-IUL)$$
\text { Sala 2W4 - D | ISCTE-IUL - Av. das Forças Armadas }
$$$$
\text { 1649-026 Lisboa, PORTUGAL }
$$ 
corresponde apenas aos estabelecimentos com mais de 10 camas. De um modo geral estão aqui as antigas pensões reclassificadas de hostels, pelo que as cerca de 14 mil camas que o INE referencia como Alojamento Local não correspondem a um acréscimo de capacidade de alojamento resultante do florescimento recente desta atividade na cidade.

Considerando como acréscimo de fluxos turísticos associados ao AL os assegurados por estabelecimentos com menos de 10 camas, conclui-se que o AL terá neste momento uma capacidade de alojamento equivalente à da hotelaria tradicional, embora com um número ligeiramente menor de dormidas. Estes números resultam de uma estimativa onde se admite existirem na cidade cerca de 18 mil estabelecimentos de AL com menos de 10 camas e uma capacidade média de acolhimento de 3 hóspedes. A base de dados do RNAL e o inquérito que realizámos sustentam esta estimativa. Por outro lado, o INE calcula que a taxa de ocupação do AL em 2016 foi de 48,9\% (inferior aos 62,4\% da hotelaria convencional), e considera como estadia média dos visitantes 2,4 dias. Com base nestes parâmetros somos levados a pensar que o AL atraí à cidade cerca de 4 milhões de turistas, assegurando cerca de 10 milhões de dormidas por ano.

Tabela 9 - Indicadores de atividade turística na cidade de Lisboa, 2016

\begin{tabular}{|c|c|}
\hline Hotelaria (sem AL) & \\
\hline Capacidade alojamento & 51.627 \\
\hline $\mathrm{N}^{\mathrm{o}}$ de hóspedes (milhares) & 4.568 \\
\hline $\mathrm{N}^{\mathrm{o}}$ de dormidas na hotelaria (milhares) & 11.066 \\
\hline Média diária de dormidas & 30.318 \\
\hline Alojamento Local (<10 camas) & \\
\hline Capacidade alojamento- AL & 54.000 \\
\hline $\mathrm{N}^{\mathrm{o}}$ de hóspedes-AL (milhares) & 4.106 \\
\hline $\mathrm{N}^{\mathrm{o}}$ de dormidas AL (milhares) & 9.855 \\
\hline Média diária de dormidas & 27.000 \\
\hline Impacte demográfico & \\
\hline População residente, 2016 (milhares) & 505 \\
\hline Entradas pendulares (milhares) & 426 \\
\hline Entradas pendulares/Residentes & 84,4 \\
\hline Dormidas turistas/Residentes & 11,4 \\
\hline
\end{tabular}

Fonte: cálculos do autor com base em TP (2017), Inquérito próprio e INE (2017) Anuário Estatístico da AML, 2016

\footnotetext{
DINÂMIA'CET - IUL, Centro de Estudos sobre a Mudança Socioeconómica e o Território do Instituto Universitário de Lisboa (ISCTE-IUL)$$
\text { Sala 2W4 - D | ISCTE-IUL - Av. das Forças Armadas }
$$$$
\text { 1649-026 Lisboa, PORTUGAL }
$$$$
\text { Tel. (+351) } 210464031 \text { - Extensão } 293101 \text { | E-mail: dinamia@iscte-iul.pt | www.dinamiacet.iscte-iul.pt }
$$ 
Se, por hipótese académica, os fluxos turísticos anuais se distribuíssem uniformemente pelos 365 dias do ano, os cerca de 9 milhões de turistas que geram 20 milhões de dormidas na cidade, corresponderiam a um acréscimo médio da população residente de que ordem? A resposta, visível na Tabela 9, é que o fluxo turístico representa um acréscimo da ordem dos $11 \%$ do número de residentes habituais na cidade. Destes $11 \%$, só ligeiramente menos de metade se fica a dever à atividade de AL. Um acréscimo desta magnitude é, obviamente, muito significativo. Mas não parece que daqui se possa inferir que existe excesso de turismo na cidade. Sobretudo quando comparamos os cerca de 60 mil turistas que em média deambulam diariamente pelas ruas da cidade, com os 426 mil trabalhadores que todos os dias vêm trabalhar para Lisboa, deslocando-se de forma pendular entre a cidade e os concelhos onde residem.

Podemos, pois, concluir que não é correto afirmar-se que existe demasiado turismo em Lisboa, menos ainda que a causa disso é a oferta de AL existente. Questão diferente é saber se o AL está, ou não, a contribuir para a desertificação humana do centro histórico da cidade.

É comum a acusação de que os antigos residentes têm vindo a ser expulsos das casas que que habitavam, sendo estas convertidas em espaços de AL. Já antes se sublinhou, Tabela 1, que existe uma elevada concentração do AL num espaço reduzido da cidade. Quase metade dos estabelecimentos de AL localizam-se nas duas freguesias correspondentes ao Centro Histórico, estando $75 \%$ ou no centro ou na coroa envolvente imediata. É aliás nestas duas zonas que se concentram os estabelecimentos de maior dimensão física e empresarial: $78 \%$ da oferta com capacidade para alojar mais de 10 pessoas está localizada no Centro Histórico ou no Arco Central; 62\% da oferta do grupo D (empresas de maior dimensão) que antes se definiu, localiza-se apenas na zona do Centro Histórico (os restantes grupos têm uma distribuição que acompanha o padrão de localização geral). É também no Centro Histórico que se concentram os proprietários multi-estabelecimento: em 53\% dos casos, quem tem 2 ou 3 AL localiza-se no Centro Histórico. Quando são 4 ou mais, a proporção sobre para 63\%. Há, portanto, uma sobre representação na zona histórica da cidade do segmento empresarial do AL que antes se definiu.

Em todo o caso, não parece haver uma relação direta entre tipologia de negócio e multiplicação de espaços de AL no mesmo edifício. Em quase 2/3 dos prédios em que está instalado um apartamento de $\mathrm{AL}$, existe mais do que um estabelecimento. Mas não existe nenhuma relação clara entre o número de $\mathrm{AL}$ no mesmo prédio e a capacidade de alojamento total dos proprietários. Existe, sim, uma relação significativa com a tipologia de espaços: $68 \%$ dos AL instalados num prédio onde existe mais do que um estabelecimento, são espaços com uma capacidade máxima de alojamento para 4 pessoas.

Registe-se também que não há um padrão geográfico definido para as situações de conflitos de vizinhança. Quase 3/4 dos inquiridos diz nunca ter tido problemas de vizinhança, e apenas $25 \%$ afirma tê- 
los tido, embora "raramente" ou "às vezes". De entre os que reconhecem a existência de problemas, não se observa um padrão geográfico de maior incidência, pese embora uma ligeira concentração dos conflitos na "coroa exterior" (e não no "Centro" onde o AL está mais concentrado).

A inexistência de uma relação clara entre concentração do AL e conflituosidade com os vizinhos, pode explicar-se por muitos dos apartamentos estarem desocupados. No Censo de 2011 o INE apurou que havia na AMLisboa 185 mil casas vazias (sendo que apenas 20\% estavam disponíveis para arrendamento). Em Lisboa havia 86 mil apartamentos familiares não ocupados em permanência. Se tivermos em conta que $47 \%$ dos espaços de AL na cidade funcionam em apartamentos que não tinham condições de habitação, então os apartamentos deslocados do "mercado" residencial para o AL corresponderão apenas a cerca de $12 \%$ das casas desocupadas no início da presente década. Um estudo recente (UNL, 2016), usando a base de dados do RNAL que aqui utilizamos, bem como a informação dos $\mathrm{AL}$ disponíveis na plataforma AirBnB, conclui que os apartamentos afetos ao AL corresponderão no máximo a $20 \%$ dos apartamentos residenciais existentes na zona que aqui designamos por centro histórico, e a cerca de $10 \%$ na coroa central imediata. Daqui decorre que parece excessivo dizer-se que foi o AL que despovoou o centro da cidade. A proporção de apartamentos ocupados pelo AL está longe de ser dominante, e ocupará apenas uma pequena proporção dos apartamentos familiares há muito tempo desocupados. Tal sugere que a relação causal poderá ter sido diferente: não foi o AL que expulsou os residentes do centro da cidade, foi o AL que permitiu a reabilitação de parte do património edificado nessa zona da cidade, que, entretanto, se tinha degradado e levado à sua desocupação. Vejamos o que nos dizem os dados estatísticos sobre isto.

Tomando por referência a avaliação bancária dos apartamentos T2 (tipologia que mais se aproxima do utilizado pelo AL) o $\mathrm{m} 2$ da habitação em Lisboa é $75 \%$ superior ao valor médio nacional (INE, 2017). Será o AL que explica os elevados preços da habitação em Lisboa? Não parece que assim seja. Analisando o preço/m2 da habitação na AML (veja-se infografia, Expresso 3 fevereiro de 2018) a diferença de preços face a Lisboa parece explicar-se pela conjugação de dois fatores: a centralidade/acessibilidade à cidade de Lisboa, e a imagem socialmente percecionada da qualidade urbanística do local. Olhando para o interior da cidade de Lisboa o mesmo se verifica: o preço reduz-se à medida que nos afastamos do centro histórico da cidade e/ou a imagem de prestígio/qualidade do bairro diminui. Esta relação prevalece face à relação incidência do AL versus preço por m2 da habitação. Comparem-se os preços de S. Vicente de Fora com os do Parque das Nações. Ao contrário de S. Vicente de Fora, na zona do Parque das Nações existem poucos estabelecimentos de AL, porém aqui o preço por m2 da habitação é mais elevado em 33\%.

\footnotetext{
DINÂMIA'CET - IUL, Centro de Estudos sobre a Mudança Socioeconómica e o Território do Instituto Universitário de Lisboa (ISCTE-IUL)

Sala 2W4 - D | ISCTE-IUL - Av. das Forças Armadas 1649-026 Lisboa, PORTUGAL 
O problema é que, como se indica na Tabela 10, o stock de alojamentos familiares na cidade estagnou nos 323 mil. Por exemplo, em 2016 apenas foram concluídos 47 novos fogos para habitação correspondente à tipologia To, T1 ou T2 (as mais procuradas para AL). Não obstante, nesse ano foram transacionados mais de 12 mil alojamentos familiares em propriedade horizontal, um valor muito acima do crescimento dos estabelecimentos de AL.

Tabela 10 - Dinâmica imobiliária da cidade de Lisboa

\begin{tabular}{|l|l|}
\hline $\begin{array}{l}\text { Stock alojamentos familiares, 2011 } \\
\text { Stock alojamentos familiares, 2016 }\end{array}$ & 322.944 \\
Fogos novos para habitação: T0/T1/T2 (2016) & 47.580 \\
No alojamentos comprados em propriedade horizontal (2016) & 12.140 \\
$\begin{array}{l}\text { Reconstruções edifícios, total: licenciados, 2016 } \\
\text { Reconstruções edifícios, habitação: licenciados, 2016 } \\
\text { Reconstruções edifícios, total: concluídos, 2016 } \\
\text { Reconstruções edifícios, habitação: concluídos, 2016 }\end{array}$ & 314 \\
Reconstruções em \% construções novas para hab: 2014-2016 & 102 \\
Stock alojamentos habitação social & $79,1 \%$ \\
\hline
\end{tabular}

INE (2017) Anuário Estatístico da AML, 2016

Tomando como referência os indicadores do mercado imobiliário veiculados pela imprensa (DN, 11 janeiro 2018), 37\% dos apartamentos transacionados na cidade foram adquiridos por estrangeiros, o que equivale a cerca de 4500 apartamentos, só no ano de 2016. A compra de habitação por cidadãos estrangeiros tem vindo a ser estimulada pela política fiscal em Portugal, e, na cidade de Lisboa, a pressão inflacionária resultante desta procura é claramente superior ao efeito inflacionário decorrente do crescimento do AL, como os números anteriores bem documentam. No mesmo sentido aponta outro indicador. Nas zonas de concentração da atividade de AL predominam edifícios antigos, pelo que presumivelmente os apartamentos de AL tenderão a resultar não de construções novas, mas de imóveis reabilitados. Ora, no período 2014-2016, o volume de espaços reconstruídos para habitação na cidade de Lisboa corresponde apenas a 17\% do número de construções novas para habitação. Mesmo que todas as casas reabilitadas fossem afetas ao AL, não poderia atribuir-se ao AL a razão de ser do preço atual da 
habitação na cidade. Mais depressa o problema está associado à escassez de oferta de habitação social, que representa apenas $8 \%$ do parque habitacional da cidade, e, por norma, localizada fora da zona da cidade que vem sendo eleita pelo AL.

Será que os casos da amostra de estudo do AL que temos vindo a analisar corroboram a leitura dos indicadores gerais anteriores? Concentremos a nossa atenção na dinâmica imobiliária associada ao investimento no $\mathrm{AL}$ em Lisboa.

Cerca de $44 \%$ dos estabelecimentos de AL ocupam espaços que anteriormente estavam desocupados. Os restantes ou eram residência do proprietário, $35 \%$, ou estavam arrendados $21 \%$ (1/5 dos quais para fins comerciais). Note-se que em 2011 no Concelho de Lisboa os alojamentos familiares arrendados eram 42\%, mais do dobro do observado no país (INE, 2013), pelo que a transferência de apartamentos do mercado de arrendamento habitacional para o AL é claramente menos do que proporcional à \% de habitação arrendada na cidade (16\% versus $42 \%$ ). Acresce que apenas pouco mais de metade (53\%) dos espaços ocupados por AL eram anteriormente espaços com condições para serem habitados. Destes $51 \%$ constituíam o espaço de residência dos seus proprietários, repartindo-se os restantes em partes iguais entre os que estavam desocupados e os que estavam arrendados (24\%). Como resultado, em quase metade das situações (47\%) a criação do negócio implicou a reabilitação do património edificado, sendo que, quando tal aconteceu, anteriormente $65 \%$ desses espaços estavam desocupados. Às obras requeridas pela situação anterior do espaço, juntam-se as que os proprietários de AL fizeram em espaços que estavam habitáveis. No total terão sido realizadas obras de melhoria em $70 \%$ dos espaços ocupados por AL.

No caso específico da zona correspondente ao centro histórico de Lisboa, a proporção dos AL instalados em espaços que estavam desocupados (54\%), ainda é superior à do conjunto (44\%). A proporção dos espaços anteriormente arrendados acompanha o padrão geral de distribuição do AL pelas 3 zonas da cidade que definimos, enquanto que a substituição direta de alojamento familiar dos proprietários (anteriores ou atuais) aconteceu sobretudo na coroa exterior da cidade. As obras de reabilitação incidiram sobretudo no centro histórico (54\%), enquanto que as pequenas obras de melhoria aconteceram sobretudo na coroa exterior da cidade, o que está diretamente relacionado com a idade do património edificado.

Em síntese, o AL na cidade de Lisboa é o elo comum de um processo de despovoamento, acompanhado de um outro processo de redinamização económica da cidade e de reabilitação do património edificado. O testemunho espontâneo que recebi de um dos inquiridos neste estudo fornece uma boa ilustração das várias incidências da dinâmica do AL: 
Tive um alojamento local na Mouraria. Antes de comprar o apartamento, este tinha estado desocupado e a degradar-se durante 14 anos. Formei o condomínio do prédio, liderei o arranjo do telhado, pintura da fachada e arranjos estruturais. Nada disto teria sido possível sem o apoio financeiro e o tempo dedicado ao AL. Por motivos vários, decidi vender o apartamento, e este passou para o mercado imobiliário. Uma família portuguesa ofereceu 200 mil euros, e um investidor estrangeiro ofereceu 300 mil euros. O apartamento irá para um senhor inglês, que virá passar 4 meses por ano no mesmo, e o alugará o resto do tempo através de publicidade feita em Inglaterra.

Os números que acabam de ser apresentados desautorizam o discurso de quem responsabiliza o AL pelo despovoamento do centro da cidade. E se dúvidas restassem, elas seriam esclarecidas pela informação da Tabela 11.

Desde 1985 que a cidade de Lisboa tem vindo, continuamente, a perder população. De tal forma que o número atual de eleitores corresponde a menos de 3/4 dos que residiam na cidade há apenas $1 / 4$ de século atrás. Este processo tem incidido particularmente no Centro Histórico, onde os eleitores atuais são apenas 45\% dos que existiam em 1993. Por conseguinte, é indiscutível que está em curso um processo de despovoamento da cidade. O que não é correto é atribuir-se ao turismo, e menos ainda ao AL pelas razões já vistas, a responsabilidade por este despovoamento.

Tabela 11 - Evolução do número de eleitores no concelho de Lisboa e no Centro Histórico

\begin{tabular}{|l|l|l|l|l|l|l|l|}
\hline & 1993 & 2005 & 2013 & 2017 & $2017 / 93$ & $2017 / 2005$ & $2005 / 93$ \\
\hline Lisboa & 662797 & 536450 & 508847 & 491900 & 74,2 & 91,7 & 80,9 \\
\hline Centro Histórico & 48098 & 31768 & 25799 & 21663 & 45,0 & 68,2 & 66,0 \\
\hline tmca (\%) & & & & & & & \\
\hline Lisboa & & & & & $-1,23$ & $-0,72$ & $-1,75$ \\
\hline Centro Histórico & & & & & $-3,07$ & $-3,06$ & $-3,07$ \\
\hline
\end{tabular}

Fonte: Cálculos próprios com base em CNE-Mapa oficial da CNE-Eleições Autárquicas

Com efeito, o surto de crescimento do turismo na cidade aconteceu depois do Euro2004. Ora, o ritmo de perda de população de Lisboa entre 1993 e 2005 (antes do surto turístico, portanto) é 2,4 vezes superior à perda verificada nos últimos 12 anos. Se nos focarmos na zona onde o despovoamento foi mais intenso, o Centro Histórico, verificamos que o ritmo de perda de população nesta zona de concentração do AL se mantém elevado ao longo de todo o período, mas que até foi mais intenso antes do surgimento da 
recente dinâmica de crescimento do turismo e do AL. Ou seja, será necessário identificar outras causas, que não o AL, para o processo de despovoamento em curso. O que requer estudos que estão por fazer, desde logo para se saber se há efetivamente falta de oferta habitacional no Centro Histórico, ou se, pelo contrário, existem espaços habitacionais devolutos por falta de procura com condições económicas aceitáveis para os seus proprietários. Qual o perfil de quem gostaria de viver nesta zona da cidade? Esse perfil é compatível com as condições funcionais dos edifícios nas condições em que se encontram? Que perfil e motivações têm os atuais (novos?) proprietários?

Aqui chegados, estamos perante dois factos: cada vez há mais espaços de AL na zona histórica da cidade, onde, simultaneamente, cada vez há menos residentes permanentes. Daí que possamos pensar que a criação de interdições legais à atividade do AL nesta zona da cidade pudesse resultar numa alternativa política para resolver o problema habitacional. Questionámos os inquiridos por forma a poder discutir esta hipótese, através da pergunta: "Pensando num horizonte de 3 a 5 anos, se por alguma razão tiver de acabar com o negócio do AL, qual dos seguintes destinos lhe parece mais provável para o espaço agora usado como $A L$ ? ”. Para os vários destinos identificados como possíveis, foi dada aos inquiridos 4 opções de resposta: "de certeza que não", "é pouco provável”, "é muito provável”, "de certeza que sim”.

Note-se que as respostas obtidas têm como pano de fundo um cenário moderadamente otimista de evolução do mercado. Há 39\% dos inquiridos a acreditar que nos próximos 3 anos o negócio vai manterse como atualmente, enquanto $37 \%$ tem como expetativa que o negócio vai melhorar, e apenas $24 \%$ tem uma perspetiva negativa sobre o futuro. Não obstante, confrontados com a hipótese de terem de encerrar o negócio do AL:

- A convicção mais fortemente expressa pelos proprietários é a recusa da ideia de colocar o imóvel no mercado de arrendamento comercial $((81 \%=$ "de certeza que não"), ou mesmo de o deixar desocupado.

- Cerca de $35 \%$ recusa a ideia de vir a reutilizar o espaço como residência própria, (ou dos filhos), a que se juntam 33\% que considera essa hipótese "pouco provável", sendo que nos três tipos de localização (Centro Histórico, Arco Central, Coroa Exterior) são sempre mais os que a entendem como "pouco provável”, do que os que admitem como "muito provável” fazê-lo.

- Apenas $15 \%$ admite que "de certeza" colocaria o apartamento à venda, a que se juntam $25 \%$ que considera "muito provável" fazê-lo. O grupo maioritário (31\%) diz que "de certeza" não venderia. Os proprietários do Centro Histórico são os que mais tenderiam a colocar o apartamento no mercado imobiliário, o que é coerente com as respostas anteriores.

\footnotetext{
DINÂMIA'CET - IUL, Centro de Estudos sobre a Mudança Socioeconómica e o Território do Instituto Universitário de Lisboa (ISCTE-IUL)

Sala 2W4 - D | ISCTE-IUL - Av. das Forças Armadas 1649-026 Lisboa, PORTUGAL

Tel. (+351) 210464031 - Extensão 293101 | E-mail: dinamia@iscte-iul.pt | www.dinamiacet.iscte-iul.pt
} 
- A hipótese de converter os apartamentos de AL em espaços de quartos para estudantes divide opiniões, mas há uma forte tendência para a recusar. É no Arco Central que existem mais proprietários a admitir fazê-lo, e mesmo assim apenas $35 \%$.

- O cenário de colocar os espaços de AL no mercado de arrendamento de longa duração é, de todos os cenários, o que reúne maior acolhimento, ainda que longe de gerar consenso. Com efeito $48 \%$ dos AL do Centro Histórico, 50\% dos da Coroa Exterior e 55\% dos do Arco Central tenderiam a ir para o mercado de arrendamento, sendo esse o destino que os seus proprietários tomam como certo (13\%, em média) ou como "muito provável" (38\%). Os restantes proprietários (cerca de metade) dividem-se em dois grupos equivalentes, um que está certo de não colocar os imóveis no mercado de arrendamento, e outro que entende que isso é "pouco provável”.

\section{CONCLUSÕES E IMPLICAÇÕES PARA AS POLÍTICAS PÚBLICAS}

O presente estudo foi norteado pelo objetivo de compreender a dinâmica socioeconómica do AL, bem como o seu efeito na dinâmica demográfica da cidade de Lisboa.

A primeira evidência dos números apurados é de que o AL é uma atividade económica da maior relevância para a coesão do tecido social da cidade de Lisboa. Cerca de 3/4 do AL na cidade é gerido numa lógica de negócio familiar, onde pontificam famílias da classe média e mesmo média baixa, desempenhando as receitas do $\mathrm{AL}$ uma contribuição muito relevante enquanto complemento dos rendimentos do trabalho dessas famílias. Por conseguinte, uma alteração radical das condições de enquadramento económico e geopolítico internacional, ou a adoção de políticas públicas que inviabilizem o funcionamento do AL enquanto negócio familiar, terá profundas consequências na coesão do tecido social da cidade de Lisboa.

Relativamente à questão do despovoamento, face aos números apresentados na secção anterior, não poderá dizer-se com propriedade que o despovoamento da zona histórica de Lisboa se deve ao AL. Claro está que o AL não levou novos residentes para o centro da cidade, mas terá contribuído, direta e indiretamente, para a requalificação urbanística da cidade. Diretamente pelo número de edifícios reabilitados (cerca de 2/3 deles desocupados), indiretamente pela dinâmica económica que gerou nos bairros tradicionais, levando ao surgimento de novos negócios que por sua vez reabilitaram outros imóveis. Esta dinâmica trouxe aos proprietários de imóveis no centro histórico uma nova oportunidade de valorização do seu património, o que, naturalmente, se traduziu também na subida dos preços da

\footnotetext{
DINÂMIA'CET - IUL, Centro de Estudos sobre a Mudança Socioeconómica e o Território

do Instituto Universitário de Lisboa (ISCTE-IUL)

Sala 2W4 - D | ISCTE-IUL - Av. das Forças Armadas

1649-026 Lisboa, PORTUGAL

Tel. (+351) 210464031 - Extensão 293101 | E-mail: dinamia@iscte-iul.pt | www.dinamiacet.iscte-iul.pt
} 
superfície construída, mas, seguramente, o efeito do AL nessa subida é bem menor do que o de outros fatores. Parece aliás evidente que, sem o efeito impulsionador do turismo, o centro histórico da cidade teria continuado o processo de despovoamento das últimas décadas, e a requalificação desta zona de Lisboa seria muito mais difícil pois o património construído estaria mais degradado e os agentes económicos, sem oportunidades de valorizar o investimento, estariam de costas voltadas para a cidade. São disso ilustração os quatro grandes investimentos de grupos imobiliários estrangeiros que a comunicação social noticiou nos últimos meses com incidência na Baixa de Lisboa. O quarteirão que divide o Rossio da Praça da Figueira, ou os quarteirões da Rua do Ouro onde se localizavam as sedes dos bancos BCP, BPI e CGD, totalizando cerca de 50 mil metros quadrados de construção, fazem parte da mais recente oferta imobiliária da cidade para habitação e hotelaria de luxo. Sem a valorização do património edificado que ocorreu nesta zona da cidade, não teria sido possível aos bancos envolvidos realizar mais valias muito consideráveis com a alienação dos seus edifícios históricos. Nem a reabilitação económica desta zona nobre da cidade teria ocorrido. E é ao turismo que tal se deve, mas não faz sentido dizer-se que os bancos alienaram as suas sedes no centro histórico da cidade como consequência do AL.

Por analisar neste texto fica o problema da descaracterização da cidade. O turismo mudou a face da cidade, e mudou-a em função da procura, isto é, dos gostos dos turistas. Naturalmente, os residentes sentem o desconforto dessa mudança (como de resto acontece com o autor deste texto). Mas será que os habitantes que hoje se queixam do excesso de turistas, há 15 anos, antes do surto de desenvolvimento turístico, frequentavam essas zonas da cidade? Nessa altura bairros como a Mouraria, o Martim Moniz ou o Intendente... eram zonas profundamente degradadas quer do ponto de vista do património construído quer do ponto de vista dos grupos sociais que as frequentavam. Em grande medida, os portugueses redescobriram os bairros históricos de Lisboa levados pelo trilho dos turistas estrangeiros. O que devia preocupar-nos não é o excesso de estrangeiros, mas as bolsas de falta de qualidade da oferta turística (do alojamento à gastronomia passando pela oferta cultural) que afetam a qualidade dos residentes quando querem desfrutar da cidade, e projetam uma imagem negativa da cidade nos turistas.

Destas conclusões haverá que retirar implicações políticas. A primeira destas implicações é o reconhecimento de que é preciso definir políticas públicas de combate ao despovoamento da cidade de Lisboa, e que essas políticas não só estão para além do AL, como não podem ser políticas que sacrifiquem a atividade turística na cidade, nomeadamente o AL. Os problemas da falta de habitação resolvem-se com políticas de habitação (que aqui não abordámos), não se resolvem combatendo o $\mathrm{AL}$.

Os dados recolhidos levam a concluir que um hipotético cenário de inviabilização da continuação do funcionamento do AL na cidade não aliviaria a pressão imobiliária que se sente ao nível dos preços da 
habitação. Com efeito, o aluguer em regime de quartos a estudantes ou o arrendamento residencial são as opções que os inquiridos indicam como mais prováveis, o que nos permite pensar que tal cenário poderia resultar num significativo contributo para a resolução dos problemas habitacionais da cidade. Todavia, as respostas obtidas também indiciam que os proprietários de AL encaram o seu imóvel como um ativo patrimonial que desejam rentabilizar, e não como simples meio de entesouramento. Daí que recusem a ideia de o manter desocupado, ou mesmo de vir a usá-lo como espaço residencial da família, ..., mas tal também significa que têm expetativas de fazer contratos de arrendamento residencial em boas condições financeiras, condição que ao não ser garantida retiraria o apartamento do mercado habitacional de arrendamento.

No âmbito da cidade de Lisboa há vários objetivos do interesse coletivo a assegurar pelas políticas públicas, nomeadamente, a oferta de habitação na cidade, a reabilitação do património edificado, a requalificação económica da cidade e a preservação da sua identidade cultural. Alguns destes objetivos são intrinsecamente conflituosos entre si, cabendo às autoridades públicas encontrar uma combinação virtuosa entre dinâmicas imobiliárias e dinâmicas sociais, entre dinâmicas económicas e dinâmicas culturais, entre dinamização turística e preservação da qualidade de vida dos residentes.

Tomando como referência a interseção destes desígnios coletivos com o AL, resulta claro que cabe à intervenção pública estimular o papel positivo que o AL tem vindo a desempenhar na requalificação patrimonial e económica da cidade. Mas as autoridades públicas também não poderão ignorar os efeitos indesejados do turismo nas condições de vida dos residentes, pelo que se impõe a sua regulamentação. Ora, há luz das conclusões que aqui se retiraram sobre a relevância social do AL, não é aceitável que as políticas públicas venham a sacrificar a viabilidade do AL de dimensão familiar. Tal resultaria em custos sociais sem contrapartidas relevantes na dinâmica urbanística da cidade. O que se impõe é, em sede regulamentar, distinguir claramente entre o que é AL enquanto micronegócio familiar, do que é atividade de alojamento hoteleiro de dimensão empresarial (por exemplo com base no número de camas do estabelecimento e do número de estabelecimentos pertencentes ao mesmo agregado fiscal). $\mathrm{O}$ AL que funciona essencialmente como complemento de rendimento deve ser estimulado, por enquadramentos fiscais e processuais favoráveis, já a exploração de alojamento à escala empresarial que se refugia no enquadramento legal do AL deveria ser reclassificada e tratada de forma similar à hotelaria tradicional. Desde logo na exigência de standards de qualidade na oferta que prestigiem a imagem turística da cidade e contribuam para atrair turistas com mais poder de compra. Permitir o funcionamento de espaços de alojamento que mais não são do que camaratas coletivas sem um mínimo de condições, não é seguramente um bom serviço que se presta ao turismo e à imagem da cidade.

\footnotetext{
DINÂMIA'CET - IUL, Centro de Estudos sobre a Mudança Socioeconómica e o Território

do Instituto Universitário de Lisboa (ISCTE-IUL)

Sala 2W4 - D | ISCTE-IUL - Av. das Forças Armadas

1649-026 Lisboa, PORTUGAL

Tel. (+351) 210464031 - Extensão 293101 | E-mail: dinamia@iscte-iul.pt | www.dinamiacet.iscte-iul.pt
} 
Em síntese, o AL tem um importante papel social enquanto complemento de rendimento que proporciona a alguns milhares de residentes na cidade de Lisboa, e tem igualmente revelado um significativo potencial de requalificação do património contruído nas zonas mais degradadas da cidade. Estes aspetos positivos tenderão a associar-se a alguns problemas, que afetam a qualidade de vida dos residentes na cidade, seja ao nível da pressão sobre os preços da habitação seja ao nível do congestionamento demográfico nos bairros típicos, seja ao nível dos conflitos de vizinhança. Estas dimensões deveriam levar as autoridades públicas a equacionar eventuais limites de proliferação de espaços de AL em certas zonas da cidade, a equacionar modalidades de AL convivendo com apartamentos de residentes no mesmo prédio, ou a afetação da totalidade do prédio ao AL, questões que não foram analisadas no âmbito deste texto. Mas, insiste-se, a montante destas questões, impõe-se que as políticas públicas diferenciem claramente os dois segmentos de negócio que atualmente coexistem na categoria Alojamento Local, devendo também considerar explicitamente o contexto de localização: centros históricos, zonas de forte afluência turística (Algarve), ou espaços rurais. 


\section{REFERÊNCIAS BIBLIOGRÁFICAS}

AHRESP (2017) Qualificação e Valorização do Alojamento Local, Associação da Hotelaria, Restauração e Similares de Portugal, sob coordenação de Hélia Pereira/ISCTE-IUL.

CNE (2018) Mapa Oficial da CNE: eleições autárquicas, in www.cne.pt

INE (2017) Anuário Estatístico da AML, 2016

INE-2013- Retrato Territorial de Portugal, 2011

Público (2017): 24-11-2017, entrevista ao responsável Ibérico da AirBnB

TP (2017) RNAL-Registo Nacional de Alojamento Local, Turismo de Portugal.

UNL (2016) O Alojamento Local em Portugal - Qual o fenómeno? Estudo da Nova School of Business and Economics e Faculdade de Direito para a Associação da Hotelaria de Portugal.

World Bank (2017) World Development Indicators 